\title{
A mass spectrometric investigation on some 5-substituted adamantan-2-ones
}

\author{
Roberto Martínez, Raúl Cetina, Federico Jiménez, Luis Velasco and Javier Pérez \\ Instituto de Química, Universidad Nacional Autónoma de México, Circuito Exterior, Ciudad \\ Universitaria, Coyoacán 04510, México
}

Received 2 July 1996

Revised 16 October 1996

Abstract. The mass spectrometric behavior of a series of 5-substituted adamantan-2-ones has been studied in different ionization conditions (Electron Ionization and Fast Atom Bombardment), with the aid of linked scan experiments.

\section{Introduction}

It is well known that torsional and electrostatic effects are important in determining facial selectivity in reactions of aldehydes and ketones [1-4]. 5-substituted adamantanone derivatives are compounds that have been used to study electronic effects in diasteroselectivity $[5,6]$, because their structures are an ideal substrate to investigate electronic effects in transition state energy since both faces of the carbonyl are little affected by steric effects of substitution at C5 [7-9]. In spite of this, the mass spectrometry of 2-adamantanone 5-substituted derivatives has hitherto not been investigated. This observation prompted us to prepare also some simpler compounds of this type and to investigate systematically their mass spectrometric behavior.

\section{Experimental}

The 5-substituted adamantan-2-ones were synthesized according to the described procedures [1016]. Low resolution mass spectra were recorded using a Jeol JMS-AX 505 HA mass spectrometer using the direct inlet system with an ionization energy of $70 \mathrm{eV}$, an emission current of $100 \mu \mathrm{A}$ and ion source temperature of $150^{\circ} \mathrm{C}$. Measurements of exact mass were performed on a Jeol JMS-SX 102A mass spectrometer at a resolution of 10,000 using perfluorokerosene (PFK) as an internal reference. The differences between measured and theoretical values were less than $5 \mathrm{ppm}$. Daughter ions were recorded on the same instrument using the linked scan mode. Fast Atom Bombardment mass spectra were obtained bombarding nba-acetone solutions with $6 \mathrm{keV}$ Xenon atoms [17]. 


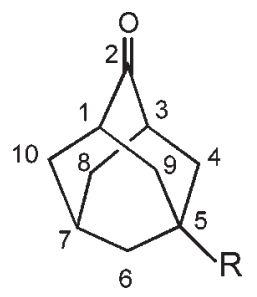

Scheme 1. R=H, OH, OMe, OAc, F, Cl, Br, I, $\mathrm{CO}_{2} \mathrm{Me}, \mathrm{Ph}$.

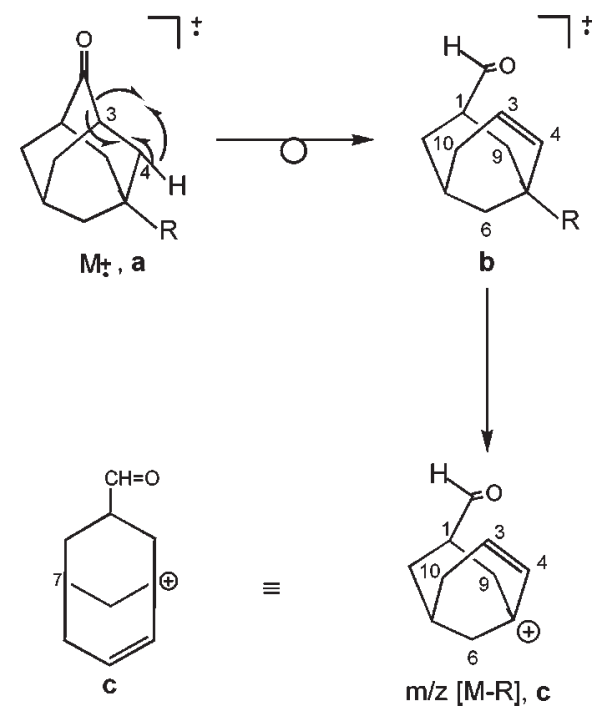

Scheme 2.

\section{Results and discussion}

The fragmentation and the specific degradations proposed for 5-substituted 2-adamantanones are depicted in schemes 2-6. The key ions and their relative abundance observed in the electron impact (El) mass spectra of compounds 1-10 are compiled in Table 1. The elemental compositions of the key ions were determined by exact mass measurements.

The 5-substituted 2-adamantanones are relatively stable under electron impact, except compound $\mathbf{8}$, and the compounds $\mathbf{1}, \mathbf{5}, \mathbf{6}, \mathbf{9}$ and $\mathbf{1 0}$ show the molecular ion a as a beak. The fission of the molecular ion a is initiated by the familiar $\alpha$-cleavage of ketones, which has been shown [18-21] to produce the most abundant fragments arising from the parent ion. In the present case, $\alpha$-fission at the $\mathrm{C} 2-\mathrm{C} 3$ bond is attended, possibly in a concerted process, together with simultaneous hydrogen migration to $\mathrm{C} 2$, leading to the central intermediate $\mathbf{b}$ (Scheme 2). This ion eliminated the 5-substituent by $\beta$-fission to $\mathrm{C} 3=\mathrm{C} 4$ double bond, yielding the species $\mathbf{c}$ at $\mathrm{m} / \mathrm{z}[\mathrm{M}-\mathrm{R}]$, the base peak of compounds $\mathbf{7}$ and $\mathbf{8}$; however this loss is completely absent in the fragmentation of $\mathbf{1}, \mathbf{3}$, and $\mathbf{5}$ analogs. This behavior may be rationalized in terms of leaving capability of the 5-R group.

The spectra further reveal the loss of water from the ion $\mathbf{c}$ to give the ion at $\mathrm{m} / \mathrm{z}\left[\mathrm{M}-\mathrm{R}-\mathrm{H}_{2} \mathrm{O}\right]$, $\mathbf{d}$. The nature of these dehydrations, which are known to proceed by a complex mechanism involving rearrangements even in simple alicyclic molecules remains unresolved [22]. The examination of 2-adamantanone incorporating deuterium in specified positions may not provide entirely decisive 

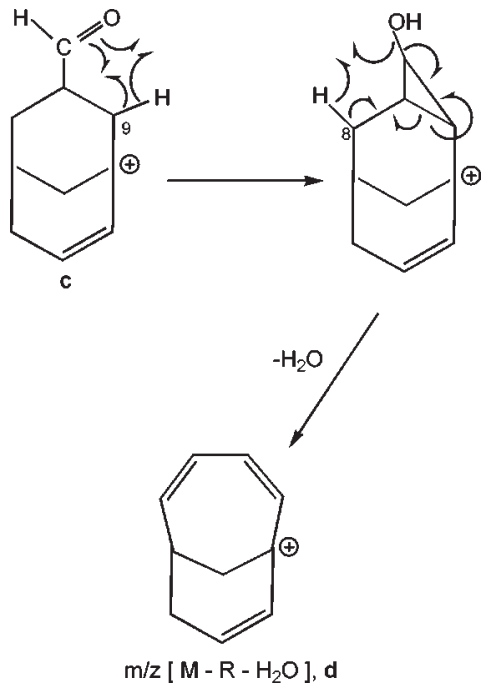

Scheme 3

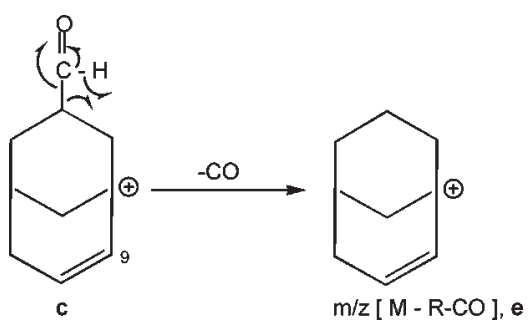

Scheme 4.

Table 1

Key ions in the EI mass spectra of 5-substituted adamantan-2-ones (1-10)

\begin{tabular}{ccrcccccc}
\hline Compound & $\mathrm{R}$ & $\mathrm{M}+\bullet$ & $\mathrm{M}-\mathrm{R}$ & $\mathrm{M}-\mathrm{R}-\mathrm{H}_{2} \mathrm{O}$ & $\mathrm{M}-\mathrm{R}-\mathrm{CO}$ & $\mathrm{M}-\mathrm{H}_{2} \mathrm{O}$ & $\mathrm{M}-\mathrm{CO}$ & {$[78-\mathrm{R}]^{+}$} \\
\hline $\mathbf{1}$ & $\mathrm{H}$ & $\mathbf{a}, \mathbf{b}$ & $\mathbf{c}$ & $\mathbf{d}$ & $\mathbf{e}$ & $\mathbf{f}$ & $\mathbf{g}$ & $\mathbf{h}$ \\
$\mathbf{2}$ & $\mathrm{OH}$ & 61.3 & 2.7 & $*$ & 2.3 & 6.1 & 3.34 & 50.9 \\
$\mathbf{3}$ & $\mathrm{OMe}$ & 49.5 & $*$ & $*$ & 3.9 & 16.0 & 5.6 & 100.0 \\
$\mathbf{4}$ & $\mathrm{OAc}$ & 11.8 & 3.7 & $*$ & 12.2 & $*$ & 6.3 & 100.0 \\
$\mathbf{5}$ & $\mathrm{F}$ & 100.0 & $*$ & $*$ & $*$ & 12.3 & \\
$\mathbf{6}$ & $\mathrm{Cl}$ & 100.0 & 10.7 & 23.6 & 11.8 & 6.2 & 7.1 & 67.5 \\
$\mathbf{7}$ & $\mathrm{Br}$ & 34.9 & 100.0 & 6.6 & 67.1 & $*$ & $*$ & $*$ \\
$\mathbf{8}$ & $\mathrm{I}$ & 2.0 & 100.0 & 2.7 & 32.6 & $*$ & $*$ & $*$ \\
$\mathbf{9}$ & $\mathrm{COOMe}$ & 100.0 & 55.0 & 10.6 & 30.4 & $*$ & 78.2 & 42.4 \\
$\mathbf{1 0}$ & $\mathrm{Ph}$ & 100.0 & $*$ & $*$ & $*$ & 4.6 & 2.0 & 76.6 \\
\hline
\end{tabular}

$*$ Relative abundance less than $2 \%$.

evidence, since extensive 'scrambling' of hydrogen and deuterium occurred under the operating conditions of the mass spectrometer [23]. In this case, it may propose the migration of one hydrogen from $\mathrm{C} 8$ and another from $\mathrm{C} 9$ to the carbonyl-oxygen; posterior, possibly in a concerted process, simultaneous fission of $\mathrm{C} 2-\mathrm{C} 3$ bond and elimination of one molecule of $\mathrm{H}_{2} 0$ gives the ion $\mathbf{d}$ (Scheme 3). Likewise, the ion $\mathbf{c}$ loses carbon monoxide to yield the ion of m/z [M-R-CO], e (Scheme 4). 
<smiles>[R]C12C=CC(CC(C=O)C1)C(C)C2</smiles>

b<smiles>[R]C1C=CC=CC1</smiles>

$\mathrm{m} / \mathrm{z}[78+\mathrm{R}], \mathbf{h}$

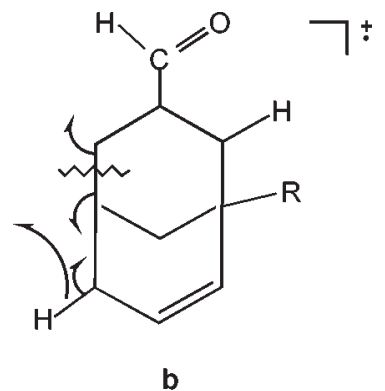<smiles>[R]C1(CC(C)C=O)C=CC=CC1</smiles>

Scheme 5 .<smiles>[R]C12CC3CC(CC(C3)C1O[CH2-])C2</smiles>

$\mathrm{M}:$, a<smiles>[R]C12C=CCC(CCC1)C2</smiles>

$\mathrm{m} / \mathrm{z}$ [M - CO], g
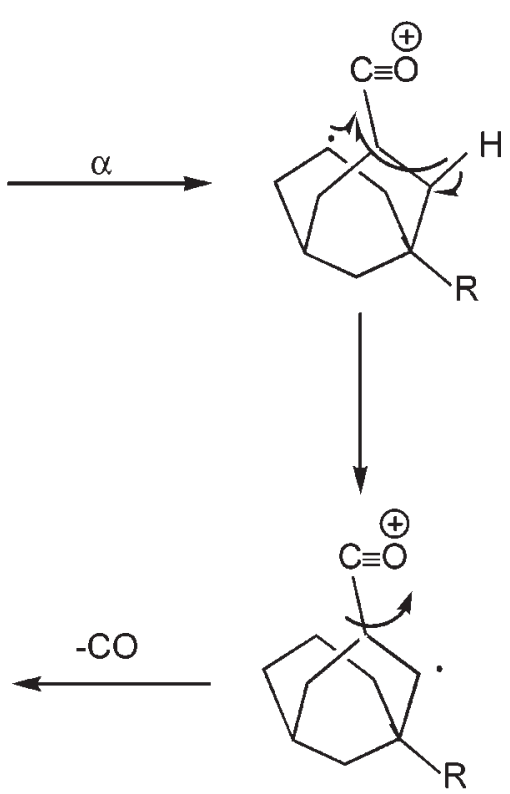

Scheme 6 . 


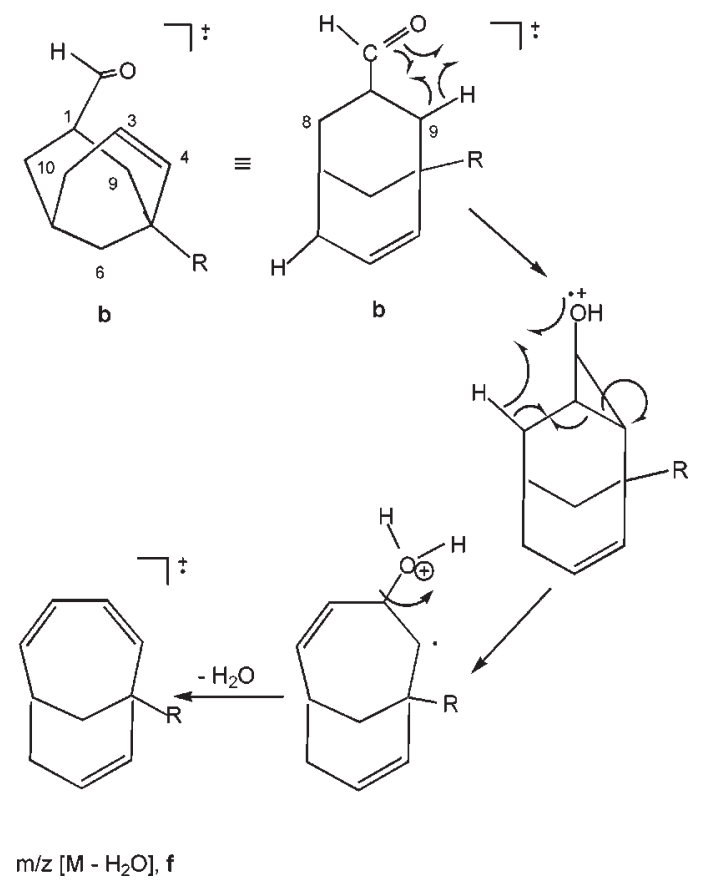

Scheme 7.

It is interesting to note that relative abundance of the ions $\mathrm{m} / \mathrm{z}\left[\mathrm{M}-\mathrm{R}-\mathrm{H}_{2} \mathrm{O}\right]$ and $[\mathrm{M}-\mathrm{R}-\mathrm{CO}]$ is high for compounds with $\mathrm{R}=\mathrm{Cl}, \mathrm{Br}$, I and COOMe.

The compounds analyzed, except 4, 7 and $\mathbf{8}$, also show a characteristic fragment at $\mathrm{m} / \mathrm{z}(78+$ $\mathrm{R})$ due to decomposition of byciclic moiety of adamantan-2-one (Scheme 5). This ion is the base peak of compounds $\mathbf{2}$ and 3. Finally, a typical expulsion of monoxide carbon and water from the molecular ions leads to the formation of the ions at $\mathrm{m} / \mathrm{z}[\mathrm{M}-\mathrm{CO}]$ and $\mathrm{m} / \mathrm{z}\left[\mathrm{M}-\mathrm{H}_{2} \mathrm{O}\right]$, respectively. This degradation pattern was previously reported for 2-adamantanone [23]. The fragmentation mechanism may be similar to that depicted for the loss of $\mathrm{CO}$ and $\mathrm{H}_{2} \mathrm{O}$ from $\mathrm{m} / \mathrm{z}[\mathrm{M}-\mathrm{R}]$ ion and it is described in Schemes 6 and 7.

The compounds examined ionized under FAB conditions showed similar mass spectral behavior as under El conditions. However, as it is known, in positive ion FAB the most favored ionization process generally consists in a protonation reaction occurring in the selvedge region close to the solution [24]. By means of metastable ions studies (parent and daugther) and accurate mass measurements the common fragmentation pattern suggested by electron impact ionization was corroborated by linked scan on FAB spectrometry.

\section{Conclusion}

From mass spectral studies, some specific points can be underlined. First, the molecular ion intensity of all the compounds analyzed, except $\mathbf{8}$, is strong. Second, the main fragmentation is determined by the 5-substituent on the 2-adamantanone moiety and by the 2-ketone group. The fragmentation pattern under FAB mass spectrometry of all the compounds studied is similar to the one under El mass spectrometry and as it is well known, they give $[\mathrm{M}+1]$ strong ions. 


\section{Acknowledgements}

We are grateful to Instituto de Química, UNAM for financial support, Contribution No. 1467.

\section{References}

[1] D.C. Wigfield, Tetrahedron 35 (1979), 449.

[2] M. Cherest, H. Felkin and N. Prudent, Tetrahedron Letters, 1968, 2199.

[3] N.T. Ahn and O. Eisenstein, Nouv. J. Chim. 1 (1977), 61.

[4] A.S. Cieplak, J. Am. Chem. Soc. 103 (1981), 4540.

[5] H. Li and W. le Noble, Rec. Trav. Chim. Pays-Bas 111 (1992), 199.

[6] J.M. Coxon, K.N. Houk and R.T. Luibran, J. Org. Chem. 60 (1995), 418.

[7] C.K. Cheung, L.T. Tseng, M.H. Lin, S. Srivastava and W. le Noble, J. Am. Chem. Soc. 109 (1987), 1598.

[8] W. Adcock and N. Trout, J. Org. Chem. 56 (1991), 3229.

[9] W. Adcock, J. Cotton and N. Trout, J. Org. Chem. 59 (1994), 1867.

[10] H.W. Geluk, Synthesis, 1972, 374.

[11] H.W. Geluk and J.L.M.A. Schlatmann, Tetrahedron 24 (1988), 5369.

[12] W. le Noble, S. Srivastava and C.K. Cheung, J. Org. Chem. 48 (1983), 1099.

[13] J.G. Henkel and J.H. Spector, J. Org. Chem. 48 (1983), 3657.

[14] F.A.J. Meskens, Synthesis, 1981, 501.

[15] H.W. Geluk, Tetrahedron Letters, 1971, 4473.

[16] K.S. Bhandari and R.E. Pincock, Synthesis, 1974, 655.

[17] M. Barber, R.S. Bordoli, R.D. Sedwick and N. Tyler, J. Chem. Soc. Chem. Commun., 1981, 325.

[18] T. Goto, A. Tatematsu, Y. Hata, R. Muneyuki, H. Tanida and K. Tori, Tetrahedron 22 (1966), 2213.

[19] C.M. Cimarusti and J. Wolinsky, J. Org. Chem. 36 (1971), 1871.

[20] A. Maquestiau, R. Flammang, P. Pauwels, P. Vallet, P. Meyrant, E.E. Kingston and J.H. Beynon, Org. Mass Spectrom. 17 (1982), 643

[21] A. Maquestiau, R. Flammang, P. Pauwels, P. Vallet, P. Meyrant, E.E. Kingston and J.H. Beynon, Org. Mass Spectrom. 20 (1985), 253.

[22] H. Budzikiewics, C. Djerassi and D.H. Williams, Mass Spectrometry of Organic Compounds, Holden Day, San Francisco, 1967, pp. 143, 159.

[23] D. Srzic, V. Vinkovic and K. Mlinaric, Rap. Commun. Mass Spectrom. 4 (1990), 500.

[24] O. Curcurutu, P. Traldi, G. Moneti, L. Carda and G. Podda, Org. Mass Spectrom. 26 (1991), 713. 


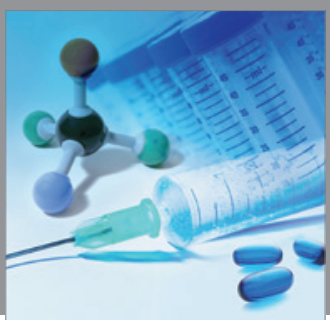

International Journal of

Medicinal Chemistry

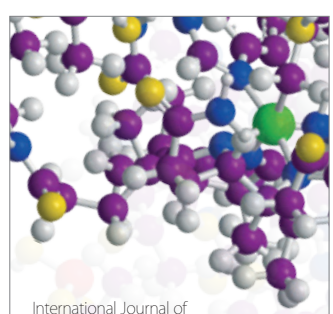

Carbohydrate Chemistry

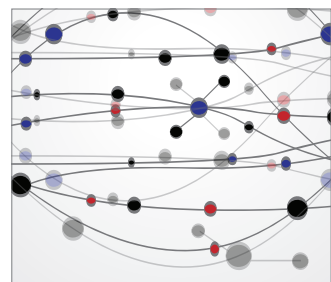

The Scientific World Journal
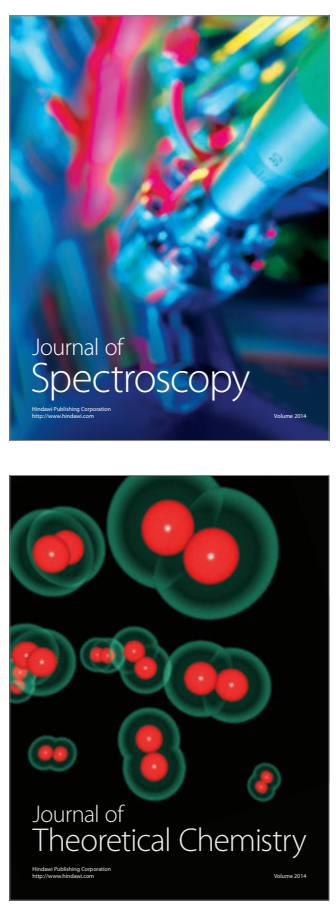
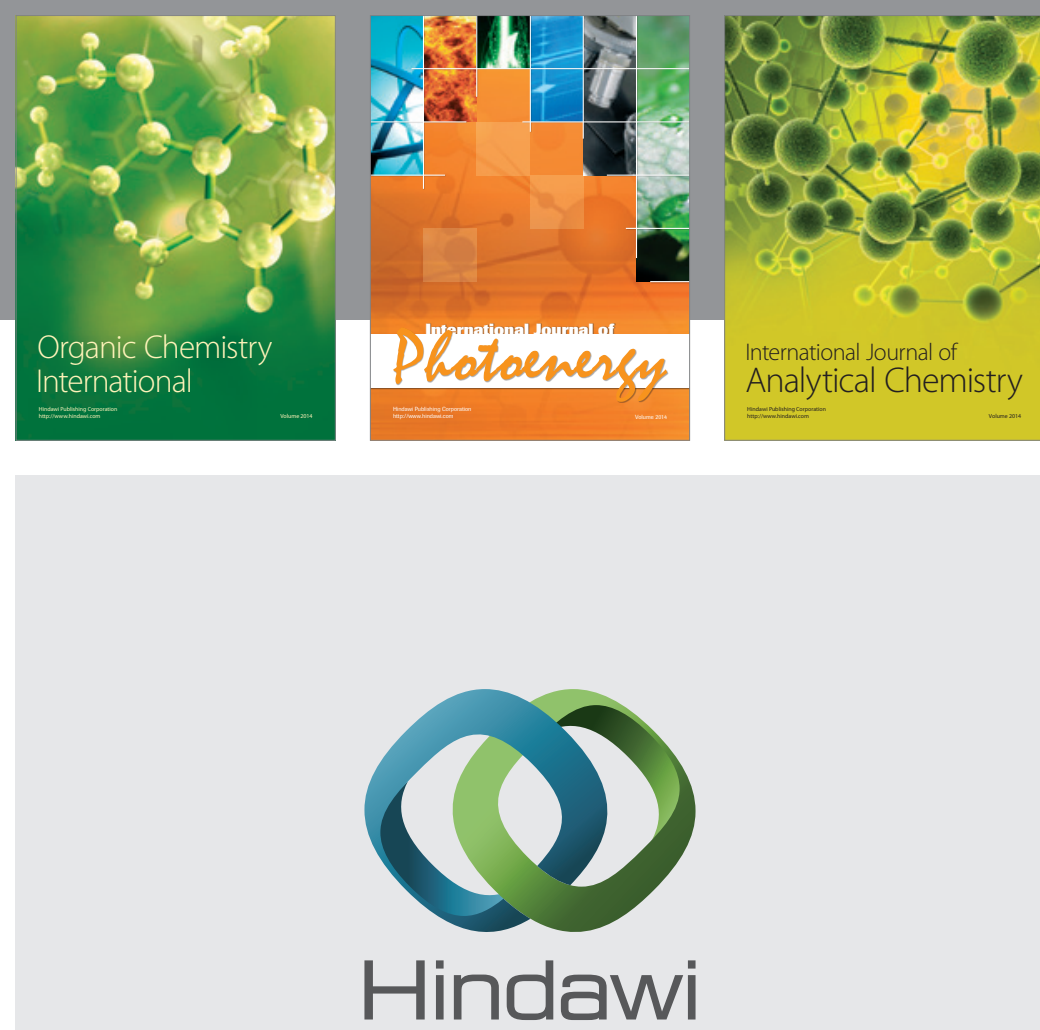

Submit your manuscripts at

http://www.hindawi.com
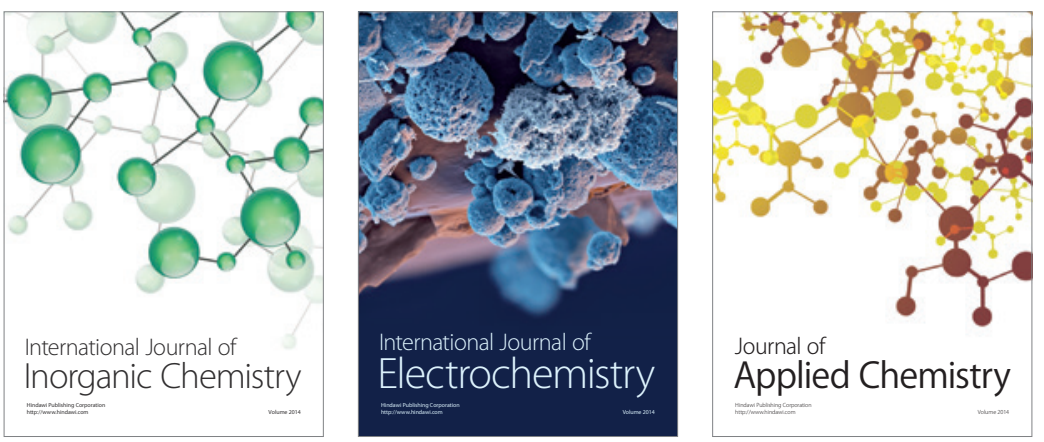

Journal of

Applied Chemistry
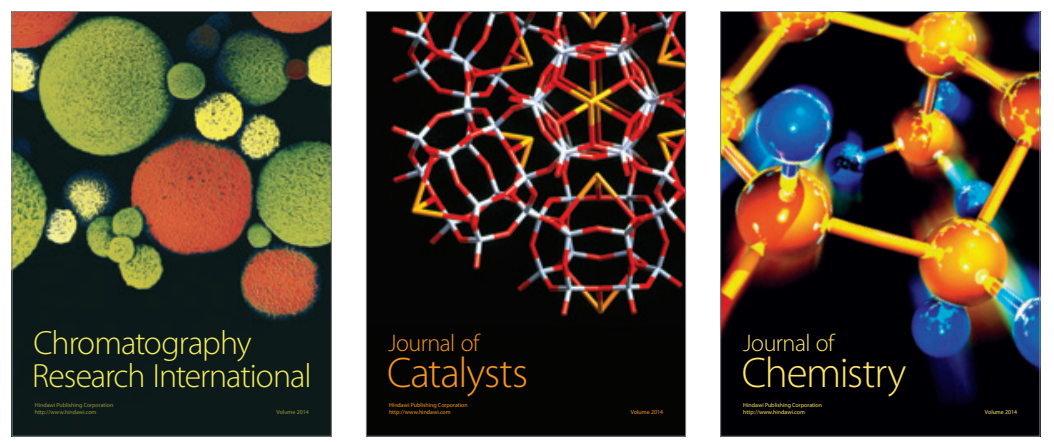
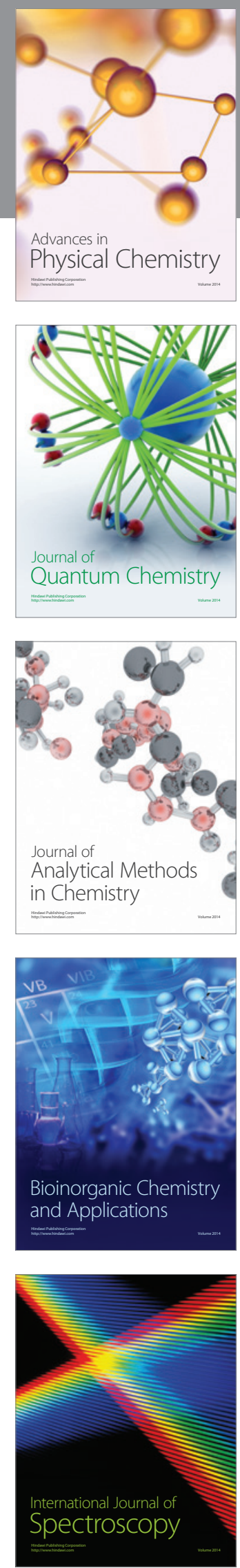